\title{
Early season estimate of influenza vaccination effectiveness against influenza hospitalisation in children, Hong Kong, winter influenza season 2018/19
}

Susan S Chiu ${ }^{1,2}$, Mike YW Kwan²,3, Shuo Feng ${ }^{4}$, Eunice LY Chan ${ }^{1}$, Huiying Chua ${ }^{4}$, Joshua SC Wong ${ }^{3}$, JS Malik Peiris ${ }^{4}$, Benjamin J

Cowling ${ }^{4}$

1. Department of Paediatrics and Adolescent Medicine, Queen Mary Hospital and Li Ka Shing Faculty of Medicine, The University of Hong Kong, Hong Kong Special Administrative Region, China

2. Authors contributed equally to the work and share first authorship

3. Department of Paediatrics and Adolescent Medicine, Princess Margaret Hospital, Hong Kong Special Administrative Region, China

4. WHO Collaborating Centre for Infectious Disease Epidemiology and Control, School of Public Health, Li Ka Shing Faculty of Medicine, the University of Hong Kong, Hong Kong Special Administrative Region, China

Correspondence: Benjamin J. Cowling (bcowling@hku.hk)

Citation style for this article:

Chiu Susan S, Kwan Mike YW, Feng Shuo, Chan Eunice LY, Chua Huiying, Wong Joshua SC, Peiris JS Malik, Cowling Benjamin J. Early season estimate of influenza vaccination effectiveness against influenza hospitalisation in children, Hong Kong, winter influenza season 2018/19. Euro Surveill. 2019;24(5):pii=1900056. https://doi.org/10.2807/1560-7917.ES.2019.24.5.1900056

Article submitted on 21 Jan 2019 / accepted on 29 Jan 2019 / published on 31 Jan 2019

The winter 2018/19 influenza season in Hong Kong has been predominated by influenza $A\left(\mathrm{H}_{1} \mathrm{~N}_{1}\right)$ pdmog as at January 2019. We enrolled 2,016 children in three public hospitals in Hong Kong between 2 September 2018 and 11 January 2019. Using the test-negative approach, we estimated high early season effectiveness of inactivated influenza vaccine against influenza A or B of $90 \%$ (95\% confidence interval (Cl): $80-95 \%$ ) and $92 \%$ (95\% Cl: 82-96\%) against influenza $\mathrm{A}\left(\mathrm{H}_{1} \mathrm{~N}_{1}\right)$ pdmo9.

In Hong Kong, the 2018/19 influenza season started in October 2018, with influenza infections reaching epidemic levels in the final week of 2018 , and influenza $A\left(H_{1} N_{1}\right) p d m o g$ viruses circulating predominantly $[1,2]$. Previous influenza $\mathrm{A}\left(\mathrm{H}_{1} \mathrm{~N}_{1}\right)$ pdmog epidemics occurred in 2012/13, 2013/14 and 2015/16 [3,4]. Here we continued an ongoing study [3-5] using the test-negative design $[6,7]$ to estimate influenza vaccine effectiveness (VE) in hospitalised children in Hong Kong in the early part of the 2018/19 winter influenza season.

\section{Study participants}

In Hong Kong, ca $90 \%$ of inpatients are treated in public hospitals. We conducted a test-negative study among children aged 6 months-17 years in three public hospitals; Queen Mary Hospital, Princess Margaret Hospital and Yan Chai Hospital, which together have a catchment area covering $\mathrm{ca} 17 \%$ of all children living in Hong Kong. We enrolled children who were admitted with a febrile acute respiratory illness (ARI) to the general paediatric wards in these three hospitals. Febrile ARI was defined as fever measured $\geq 38^{\circ} \mathrm{C}$ plus any respiratory symptom such as cough, sore throat or runny nose [3-5]. Healthcare staff collected nasopharyngeal aspirates from all enrolled children and tested for influenza viruses by reverse transcriptase PCR.

Influenza vaccination history of each patient was obtained by interviewing parents or legal guardians using a standardised questionnaire. Detailed vaccination history was further clarified by reviewing vaccination cards, contacting private clinics and/or checking electronic medical records. Children vaccinated within 6 months before hospital admission with an appropriate schedule according to the Advisory Committee on Immunization Practices [8], with the last appropriate dose at least 14 days before the hospital admission were categorised as vaccinated. Those who received influenza vaccination within 14 days of the hospitalisation were excluded from the analysis. Conditional logistic regression models were used to estimate VE, accounting for confounding by adjusting for age and age-squared and matching by calendar week. VE was estimated via 1 minus the adjusted odds ratio of vaccination [9]. All statistical analyses were performed in $R$ version 3.5.0 (R Foundation for Statistical Computing, Vienna, Austria).

The study protocol was approved by the Institutional Review Board of the University of Hong Kong/Hospital Authority of Hong Kong West Cluster and the Kowloon West Cluster Research Ethics Committee. Verbal consent was obtained from parents or legal guardians of participants.

\section{Influenza vaccine effectiveness estimate}

In order to prevent influenza infections and severe outcomes inactivated influenza vaccines (northern hemisphere formulation) are available, almost all of which 


\section{FIGURE}

(A) Influenza activity based on laboratory surveillance ${ }^{\text {(B) }}$ (B)eline of recruitment of hospitalised children with acute respiratory illness testing positive or negative for influenza virus by type/subtype, Hong Kong, 2 September 2018-11 January $2019(\mathrm{n}=2,016)$

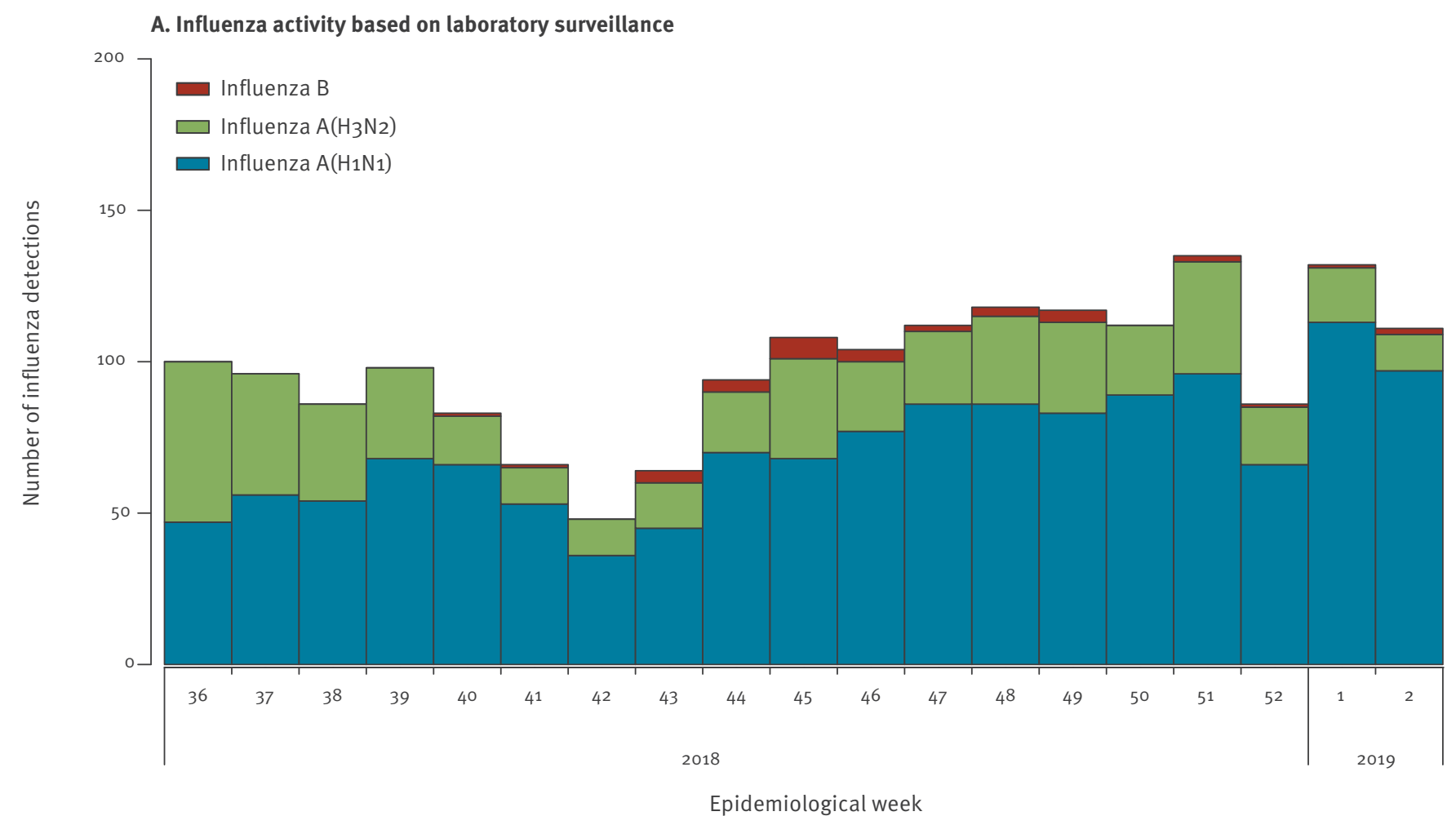

B. Timeline of recruitment of hospitalised children with acute respiratory illness testing positive or negative for influenza virus by type/subtype

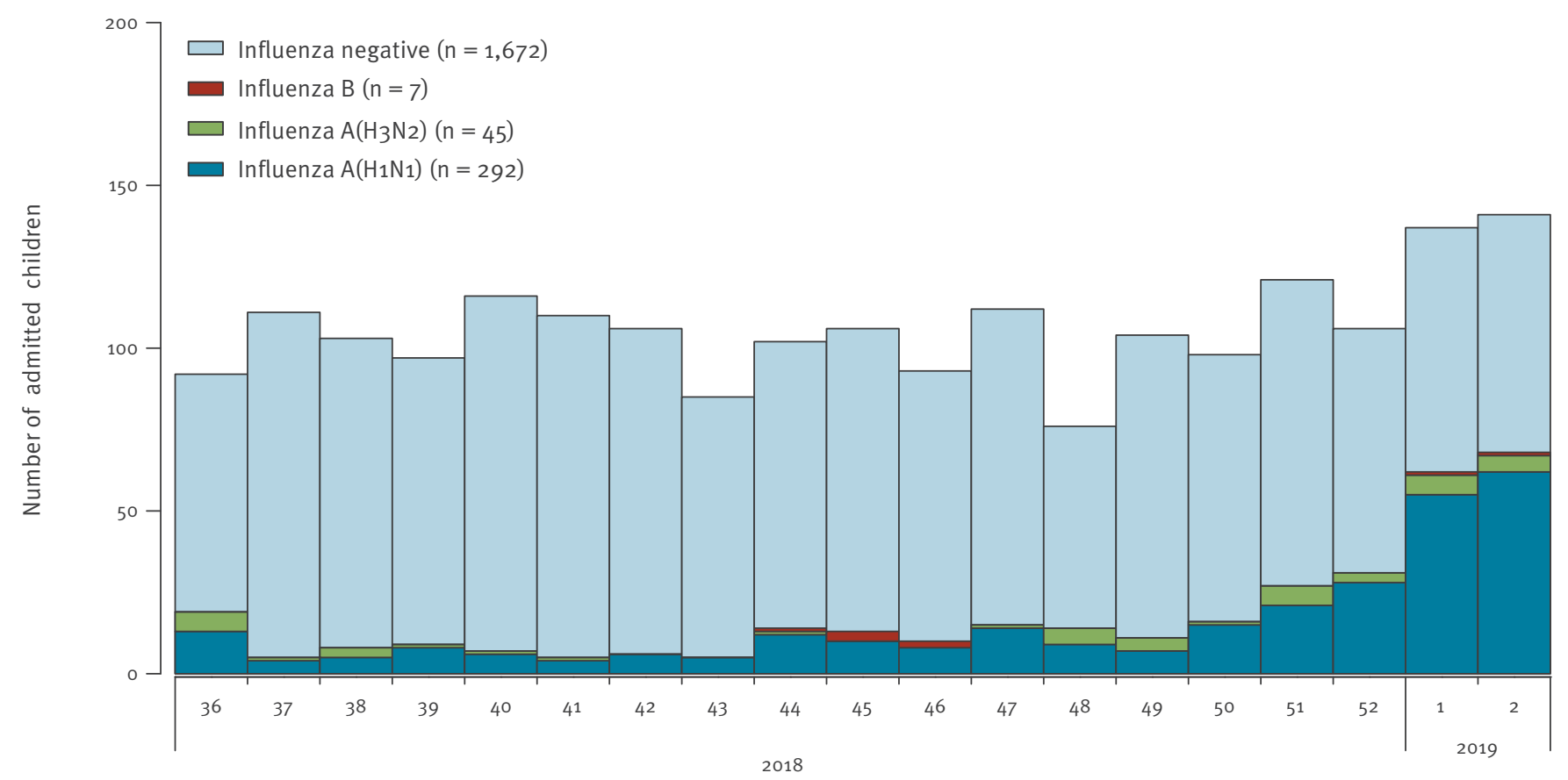

Epidemiological week

${ }^{a}$ Reported by the Public Health Laboratory Services. 
Comparison of cases testing positive for any influenza virus and test-negative controls, Hong Kong, September-December $2018(\mathrm{n}=2,016)$

\begin{tabular}{|c|c|c|c|c|c|}
\hline \multirow[t]{2}{*}{ Characteristics } & \multicolumn{2}{|c|}{$\begin{array}{l}\text { Influenza-positive } \\
\qquad \mathrm{N}=344\end{array}$} & \multicolumn{2}{|c|}{$\begin{array}{l}\text { Influenza-negative } \\
\qquad N=1,672\end{array}$} & \multirow[t]{2}{*}{$P$ value } \\
\hline & $\mathrm{n}$ & $\%$ & $\mathrm{n}$ & $\%$ & \\
\hline \multicolumn{6}{|l|}{ Age group } \\
\hline 6 months -2 years & 130 & 37.8 & 846 & 50.6 & $<0.001^{\mathrm{a}}$ \\
\hline $3-5$ years & 141 & 41.0 & 468 & 28.0 & \\
\hline $6-17$ years & 73 & 21.2 & 358 & 21.4 & \\
\hline \multicolumn{6}{|l|}{ Sex } \\
\hline Male & 159 & 46.2 & 949 & 56.8 & \\
\hline Female & 185 & 53.8 & 723 & 43.2 & $<0.001^{\mathrm{a}}$ \\
\hline \multicolumn{6}{|c|}{ Receipt of influenza vaccination ${ }^{b}$} \\
\hline Overall & 10 & 2.9 & 170 & 10.2 & $<0.001^{c}$ \\
\hline \multicolumn{6}{|l|}{ By age group } \\
\hline 6 months -2 years & 1 & 0.8 & 47 & 5.6 & \\
\hline $3-5$ years & 5 & 3.5 & 68 & 14.5 & \\
\hline $6-17$ years & 4 & 5.5 & 55 & 15.4 & \\
\hline \multicolumn{6}{|l|}{ By sex } \\
\hline Male & o & 0.0 & 94 & 9.9 & \\
\hline Female & 10 & 5.4 & 76 & 10.5 & \\
\hline
\end{tabular}

a $\mathrm{P}$ values estimated by chi-squared tests.

${ }^{b}$ Receipt of influenza vaccination defined as receipt of a quadrivalent or trivalent inactivated influenza vaccine with an age-appropriate schedule within 6 months prior to admission to one of the three study hospitals.

c $P$ value estimated by Fishers exact test.

are quadrivalent, and more than 1 million doses have been administered in Hong Kong during the 2018/19 season [10] in the local population of 7.4 million. Priority groups for vaccination include older adults, adults with chronic medical conditions, pregnant women, healthcare workers and children up to the age of 12 years.

From 2 September 2018 to 11 January 2019, a total of 2,016 children admitted to the three study hospitals were eligible to be included in the study (Figure). Of these, $344(17.1 \%)$ tested positive for influenza A or B. Among the test-positives, $85 \%$ (292/344) were positive for influenza $A\left(\mathrm{H}_{1} \mathrm{~N}_{1}\right)$ pdmog and $13 \%$ (45/344) were infected by influenza $A\left(\mathrm{H}_{3} \mathrm{~N}_{2}\right)$ viruses (Figure, Table). Among the influenza-positive children only $2.9 \%(10 / 344)$ were vaccinated, compared with $10.2 \%(170 / 1,672)$ among influenza-negative controls ( $p$ value 0.001 ). Among the 180 vaccinated children, most $(n=160: 88.9 \%$ ) received the quadrivalent inactivated influenza vaccine, compared with 10 (5.6\%) who reported receipt of a trivalent inactivated influenza vaccine and 10 (5.6\%) unknown. Influenza VE was 90\% (95\% confidence interval (Cl): 80-95) against influenza $A$ or $B$, and $92 \%(95 \% \mathrm{Cl}: 82-96)$ against influenza $A\left(\mathrm{H}_{1} \mathrm{~N}_{1}\right)$ pdmog.

To confirm that there was no evidence of a change in VE concurrent with the rising phase of the winter epidemic, we conducted a sensitivity analysis. We restricted the analysis to the 783 children admitted between 25 November 2018 and 11 January 2019. In this subgroup we estimated a VE of $87 \%(95 \% \mathrm{Cl}: 75-94)$ against influenza A or B overall and $92 \%(95 \% \mathrm{Cl}: 81-96)$ against influenza $A\left(\mathrm{H}_{1} \mathrm{~N}_{1}\right)$ pdmog.

\section{Discussion}

In this study, we found high VE for influenza $A\left(\mathrm{H}_{1} \mathrm{~N}_{1}\right)$ pdmog. Our results suggest that the influenza vaccine was effective in reducing hospitalisations due to influenza $A\left(\mathrm{H}_{1} \mathrm{~N}_{1}\right)$ pdmog in children in the early phase of the 2018/19 winter influenza season; highlighting the importance of promoting influenza vaccination in Hong Kong. Vaccination coverage was only $10 \%$ in the testnegative controls. A pilot school-based influenza vaccination programme was launched in October 2018 and expansion of this scheme could increase vaccination coverage in school-age children. Further strategies may be needed to improve vaccination coverage in children below 6 years of age, particularly in the age range of 6 months-2 years.

This is one of the first in-season estimates of influenza VE for the 2018/19 influenza season. Our findings were consistent with previous estimates against influenza $A\left(\mathrm{H}_{1} \mathrm{~N}_{1}\right)$ pdmog in children in Hong Kong from $2012 / 13$ to $2016 / 17$ [4]. In that study, we assessed VE 
estimates by different intervals between vaccination and hospitalisation and estimated a VE of $96 \%$ (95\% $\mathrm{Cl}: 74 \%-100 \%)$ against influenza $\mathrm{A}\left(\mathrm{H}_{1} \mathrm{~N}_{1}\right)$ pdmog for children vaccinated no more than 2 months before hospitalisation. In the present study, we found that most children were vaccinated 14 days -2 months before hospitalisation and that the VE estimates during the early part of the season were also high. This suggests the influenza vaccine confers strong protection soon after its administration. However, in the previous study the influenza VE declined as the season progressed, emphasising the importance of appropriate timing of vaccination $[11,12]$. Our findings were also consistent with the recently reported VE estimate of $91 \%(67 \%$ $98 \%)$ against $A\left(\mathrm{H}_{1} \mathrm{~N}_{1}\right)$ pdmog in children $1-8$ years of age in Canada for 2018/19 [13].

This study had several limitations. First, we did not have data on the genetic or antigenic characteristics for the circulating influenza $\mathrm{A}\left(\mathrm{H}_{1} \mathrm{~N}_{1}\right)$ pdmog strains in Hong Kong to compare with the A/Michigan/45/2015 $\left(\mathrm{H}_{1} \mathrm{~N}_{1}\right)$ strain included in the 2018/19 northern hemisphere formulation of the influenza vaccine. This strain was previous included in the 2017 and 2018 southern hemisphere vaccines, and the $2017 / 18$ northern hemisphere vaccine. Nevertheless, our high VE estimates suggest that substantial antigenic drift away from the vaccine strain was unlikely. Moreover, this study may have suffered sparse data bias [14] with few vaccinated and influenza-positive cases. Finally, our estimate of high VE is largely based on protection against influenza $A\left(H_{1} N_{1}\right) p d m o 9$ and we were unable to estimate $V E$ against influenza $A\left(\mathrm{H}_{3} \mathrm{~N}_{2}\right)$ or $B$ which could affect endof-season VE estimates if influenza $A\left(\mathrm{H}_{3} \mathrm{~N}_{2}\right)$ predominates later in the season.

\section{Conclusions}

In early part of the 2018/19 winter influenza season in Hong Kong, we found evidence that influenza vaccination provided very good protection against laboratory-confirmed influenza $\mathrm{A}\left(\mathrm{H}_{1} \mathrm{~N}_{1}\right)$ pdmog virus hospitalisation in children aged 6 months -17 years.

\section{Acknowledgements}

We thank Elaine Yee Lin Lo for research support.

This work was supported in part by the Research Grants Council of Hong Kong Special Administrative Region, China (Project No.T11-705/14N).

\section{Conflict of interest}

BJC reports receipt of honoraria from Sanofi and Roche for advisory boards. The authors report no other potential conflicts of interest.

\section{Authors' contributions}

Authors SSC and BJC designed the study, authors SF and $\mathrm{HC}$ performed the statistical analyses of the data, authors SSC, MYWK and BJC drafted the manuscript, SSC, MYWK, SF,
ELYC, HC, JSCW, JSMP and BJC participated in the interpretation of the analyses, read and approved the final version.

\section{References}

1. Centre for Health Protection (CHP). Flu Express. Volume 15, Number 52. Hong Kong: CHP; 2019. Available from: https:// www.chp.gov.hk/files/pdf/fluexpress_week52_3_1_2019_eng. pdf.

2. Centre for Health Protection (CHP). Flu Express. Volume 16, Number 01. Hong Kong: CHP; 2019. Available from: https:// www.chp.gov.hk/files/pdf/flux_wk1_10_1_2019_eng.pdf

3. Cowling BJ, Chan K-H, Feng S, Chan EL, Lo JY, Peiris JS, et al. The effectiveness of influenza vaccination in preventing hospitalizations in children in Hong Kong, 2009-2013. Vaccine. 2014;32(41):5278-84. https://doi.org/10.1016/j. vaccine.2014.07.084 PMID: 25092636

4. Feng S, Chiu SS, Chan ELY, Kwan MYW, Wong JSC, Leung C-W, et al. Effectiveness of influenza vaccination on influenzaassociated hospitalisations over time among children in Hong Kong: a test-negative case-control study. Lancet Respir Med. 2018;6(12):925-34. https://doi.org/10.1016/S22132600(18)30419-3 PMID: 30442587

5. Chiu SS, Kwan MYW, Feng S, Wong JSC, Leung C-W, Chan ELY, et al. Influenza vaccine effectiveness against influenza $\mathrm{A}\left(\mathrm{H}_{3} \mathrm{~N}_{2}\right)$ hospitalizations in children in Hong Kong in a prolonged season, 2016/2017. J Infect Dis. 2018;217(9):1365-71. https://doi.org/10.1093/infdis/jiyo27 PMID: 29346614

6. Jackson ML, Nelson JC. The test-negative design for estimating influenza vaccine effectiveness. Vaccine. 2013;31(17):21658. https://doi.org/10.1016/j.vaccine.2013.02.053 PMID: 23499601

7. Sullivan SG, Feng S, Cowling BJ. Potential of the test-negative design for measuring influenza vaccine effectiveness: a systematic review. Expert Rev Vaccines. 2014;13(12):157191. https://doi.org/10.1586/14760584.2014.966695 PMID: 25348015

8. Centers for Disease Control and Prevention (CDC). CDC's Advisory Committee on Immunization Practices (ACIP) Recommends Universal Annual Influenza Vaccination. Atlanta: CDC; 2010. Available from: https://www.cdc.gov/media/ pressrel/2010/r100224.htm

9. Sullivan SG, Tchetgen Tchetgen EJ, Cowling BJ. Theoretical Basis of the Test-Negative Study Design for Assessment of Influenza Vaccine Effectiveness. Am J Epidemiol. 2016;184(5):345-53. https://doi.org/10.1093/aje/kwwo64 PMID: 2758772

10. Centre for Health Protection (HCP). Statistics on $2018 / 19$ Vaccination Programmes / Schemes. Hong Kong: CHP; Last accessed on Jan 18 2019. Available from: https://www.chp.gov. hk/en/features/26734.html.

11. Rubin R. Is It Possible to Get a Flu Shot Too Early? JAMA. 2018;320(22):2299-301. https://doi.org/10.1001/ jama.2018.18373 PMID: 30477001

12. Lipsitch M. Challenges of vaccine effectiveness and waning studies. Clin Infect Dis. 2018. PMID: 30204853

13. Skowronski DM, Leir S, Sabaiduc S, Murti M, Dickinson JA, Olsha R, et al. Interim estimates of $2018 / 19$ vaccine effectiveness against influenza $A\left(\mathrm{H}_{1} \mathrm{~N}_{1}\right)$ pdmo9, Canada, January 2019. Euro Surveill. 2019;24(4):1900055. https://doi. org/10.2807/1560-7917.ES.2019.24.4.1900055

14. Greenland S, Mansournia MA, Altman DG. Sparse data bias: a problem hiding in plain sight. BMJ. 2016;352:i1981. https:// doi.org/10.1136/bmj.i1981 PMID: 27121591

\section{License and copyright}

This is an open-access article distributed under the terms of the Creative Commons Attribution (CC BY 4.0) Licence. You may share and adapt the material, but must give appropriate credit to the source, provide a link to the licence, and indicate if changes were made.

This article is copyright of the authors or their affiliated institutions, 2019. 